Article

\title{
Sustainable Management of the Electrical-Energy-Water-Food Nexus Using Robust Optimization
}

\author{
Morteza Ahangari Hassas ${ }^{1}\left(\mathbb{D}\right.$, Navid Taghizadegan Kalantari ${ }^{1, *}$, Behnam Mohammadi-Ivatloo ${ }^{2, *} \mathbb{C}$ \\ and Amin Safari ${ }^{1}$ (D) \\ 1 Department of Electrical Engineering, Azarbaijan Shahid Madani University, Tabriz 5375171379, Iran; \\ morteza.ahangar@yahoo.com (M.A.H.); safari@azaruniv.ac.ir (A.S.) \\ 2 Faculty of Electrical and Computer Engineering, University of Tabriz, Tabriz 5166616471, Iran \\ * Correspondence: taghizadegan@azaruniv.ac.ir (N.T.K.); mohammadi@ieee.org (B.M.-I.)
}

Citation: Hassas, M.A.; Kalantari, N.T.; Mohammadi-Ivatloo, B.; Safari, A. Sustainable Management of the Electrical-Energy-Water-Food Nexus Using Robust Optimization. Sustainability 2022, 14, 172. https://doi.org/10.3390/su14010172

Academic Editor: Doug Arent

Received: 17 August 2021

Accepted: 10 November 2021

Published: 24 December 2021

Publisher's Note: MDPI stays neutral with regard to jurisdictional claims in published maps and institutional affiliations.

Copyright: (c) 2021 by the authors. Licensee MDPI, Basel, Switzerland. This article is an open access article distributed under the terms and conditions of the Creative Commons Attribution (CC BY) license (https:// creativecommons.org/licenses/by/ $4.0 /)$.

\begin{abstract}
The significance of the security of electrical energy, water, and food resources in the future, which are inextricably connected, has led to increasing attention to this important issue in studies. This is an issue inattention to which can have irreparable consequences in the future. One of the sectors where electrical energy, water, and food are very closely associated is agriculture. Undoubtedly, the ability to properly manage electrical energy, hydropower, and food resources that have many uncertainties brings about the development of agriculture on the one hand and the optimal allocation of electrical energy, water, and land resources on the other. Thus, while reaching the highest economic profit, the greenhouse gas emissions reach the minimum possible value too. In this study, via robust optimization and by precisely considering the existing uncertainties, a model was developed for the optimal allocation of electrical energy, water, and land resources for a region in the north of China. In addition to acknowledging the close relationship between electrical energy, water, and food sources, the results show the method's effectiveness for sustainable management in agriculture.
\end{abstract}

Keywords: electrical-energy-water-food nexus; optimal resource allocation; robust optimization; uncertainty; sustainable management

\section{Introduction}

According to the estimations carried out, the need for electrical energy, water, and food will increase by $50 \%$ over the next 25 years because of factors like the growth of industry and urban development, the growing population, and so on [1-3]. The COVID-19 pandemic, since 2020, has accelerated the recent issue as well. Today, a significant portion of the world's freshwater resources are used in agriculture and for food production: $30 \%$ of the world's electrical energy and $90 \%$ of freshwater resources are used to produce and distribute food [4-6]. Access to freshwater sources and electrical energy has a direct and very large effect on food production. Electrical energy, water resources, and food are closely related. Having enough water has a huge effect on the availability of electrical energy and food. Energy sources, water, and food sources have each been evaluated separately in the past. The last three sources are completely related, and inattention to this connection in the future can end in irreparable problems. For integrated management of the three sources, the concept of the electrical-energy-water-food nexus was formed [7-9]. Figure 1 shows the close relationship and interdependence of different parts of an electrical-energy-waterfood nexus. The authors of [10] fully examined the concept, challenges, and perspectives in the electrical-energy-water-food nexus emphasizing the significance of attention to the inseparable relationship of these three parts in the nexus. The authors of [11] emphasized the significance of the management of an electrical-energy-water-food nexus in the agricultural sector. In this reference, the nexus was examined using a conceptual model. The authors of [12] examined the existing social and economic connections between different 
parts of an electrical-energy-water-food nexus in a city. Examining the issue of security in the electrical-energy-water-food nexus is very important for this purpose, which is why various types of the electrical-energy-water-food nexus in different countries around the world have been evaluated and modeled in references [13-16]. The interrelationships between electrical energy and water sources in a nexus have been evaluated to reduce the costs associated with hydropower plants and desalination plant installations in [17]. Sustainable management and optimization in an electrical-energy-water-food nexus is a major challenge because of the many uncertainties and interrelationships between various parts of the nexus. Using robust optimization, and specifically considering the existing uncertainties, the study developed a model for the optimal allocation of electrical energy, water, and land resources for a region in the north of China. As a result, while achieving the highest economic benefits, the greenhouse gas emissions and the causes of water pollution also reached their minimum possible values.

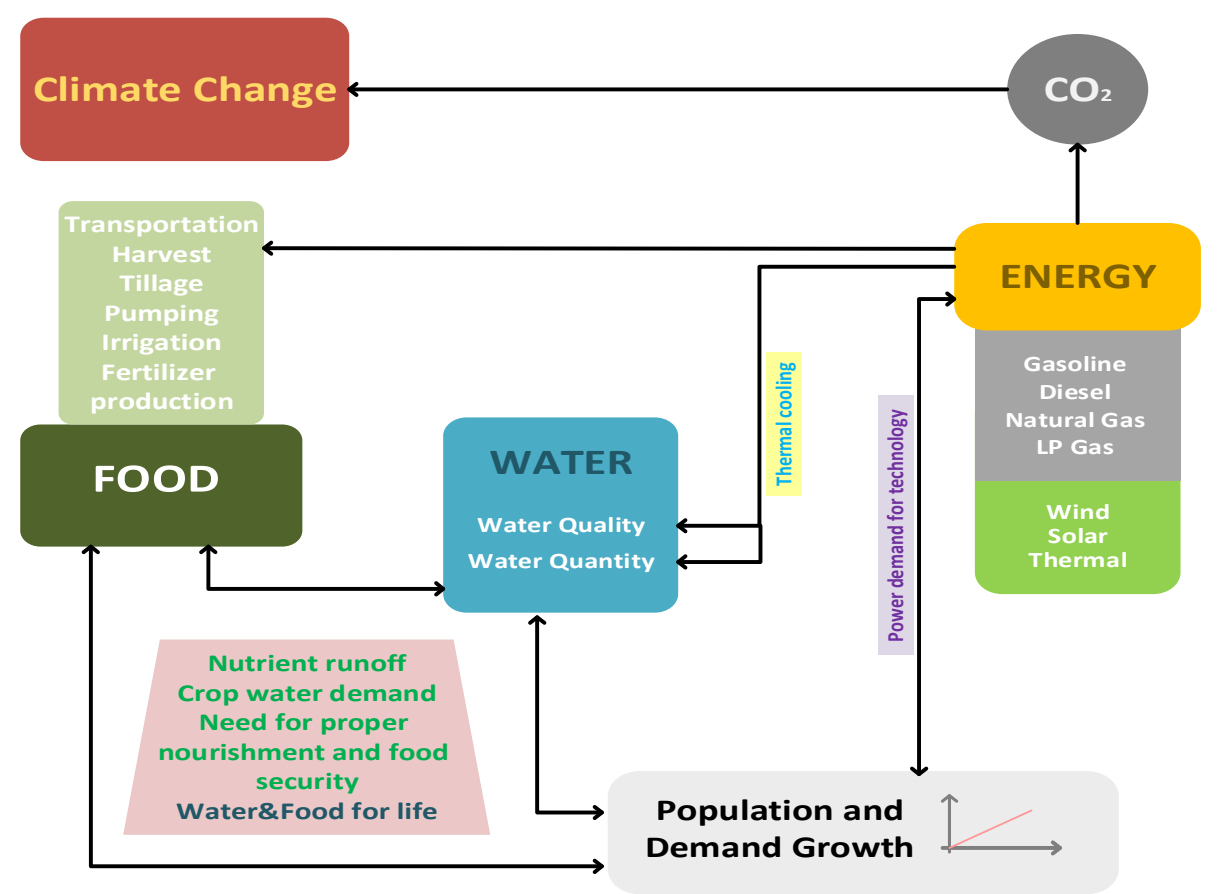

Figure 1. Interaction between various sectors of a nexus.

\section{Robust Optimization}

Robust optimization presents a different method to solve problems involving uncertain parameters. In a robust optimization problem, there is no need to know the distribution function of uncertain parameters, and having the range of changes of these parameters suffices $[18,19]$. Two important criteria were considered in designing this method:

A. Feasibility of calculations: theoretically, it is desirable if the main problem can be solved in a reasonable and possible time. A robust optimization problem has this feature.

B. Probability limits: from a probability perspective, when the uncertain parameters follow the general probability distributions, it can be guaranteed that the answer to the problem is possible and achievable.

Usually, the general structure of linear optimization problems is as follows:

$$
\begin{aligned}
& \text { Maximize } C^{T} x \\
& \text { subject to : } \\
& a_{i} x \leq b_{i}, \quad \forall i \in I, \forall a_{i} \in A, \forall b_{i} \in B
\end{aligned}
$$


Equation (1) assumes that only the elements of matrix $A$ have uncertainty. Without losing the comprehensiveness of the problem, it is assumed that the vector of the coefficients of the objective function, vector $C$, has no uncertainty. However, despite the uncertainty in the objective function coefficients, one can replace the objective function by optimizing an auxiliary variable such as $Z$ and instead add the constraint $Z-C T_{x} \leq 0$ to the problem. Consider line $i$ from the coefficient $A$ of the matrix and assume that $J_{i}$ contains the coefficients of line $i$, which are subject to uncertainty. Each element like $a_{i j}$, where $j$ is selected from the $J_{i}$ set, is modelled as a symmetric and finite variable of $\widetilde{a}_{i j}$. The variable takes a numeric value in the interval $\left[a_{i j}-\dot{a}_{i j}, a_{i j}+\dot{a}_{i j}\right][20]$.

In the following, the "Soyster" as well as the "Ben-Tal and Nemirovsky" methods for robust optimization are examined.

\subsection{Soyster Method}

The mathematical expression of the Soyster method for the uncertain optimization problem defined in Equation (1) is as follows.

$$
\begin{aligned}
& \text { Maximize } \quad C^{T} x \\
& \text { subject to: } \\
& \sum_{j} a_{i j} x_{j}+\sum_{j \in J_{i}} \dot{a}_{i j} y_{j} \leq b_{i} \quad \forall i \\
& -y_{j} \leq x_{j} \leq y_{j} \quad \forall j \\
& y \geq 0
\end{aligned}
$$

If $x^{*}$ is assumed to be the optimal answer to the above relations, then, we have $y_{j}=\left|x_{j}^{*}\right|$ for the optimality of the answer; thus,

$$
\sum_{j} a_{i j} x_{j}^{*}+\sum_{j \in J_{i}} \dot{a}_{i j}\left|x_{j}^{*}\right| \leq b_{i} \quad \forall i
$$

For any uncertain data value of $\widetilde{a}_{i j}$, the answer to the problem remains possible and achievable, which will be a robust answer, as Equation (4) demonstrates the answer to be possible and achievable for each uncertain parameter occurrence.

$$
\sum_{j} \widetilde{a}_{i j} x_{j}^{*}=\sum_{j} a_{i j} x_{j}^{*}+\sum_{j \in J_{i}} \eta_{i j} \dot{a}_{i j} x_{j}^{*} \leq \sum_{j} a_{i j} x_{j}^{*}+\sum_{j \in J_{i}} \dot{a}_{i j}\left|x_{j}^{*}\right| \leq b_{i} \quad \forall i
$$

The above robust optimization modeling is known as the Soyster method. The main drawback of this method is failure to control the number of undetermined coefficients [21].

\subsection{Ben-Tal and Nemirousky Method}

The robust optimization model proposed by Ben-Tal and Nemirovsky is a linear model that not only controls the number of undetermined coefficients but is also appropriate for robust optimization of problems with discrete variables.

To run the robust optimization model using this method, it is necessary to define the $\Gamma_{1}$ parameter as the uncertainty budget. This parameter determines the number of uncertain parameters. For instance, in the Equation (1) optimization problem, matrix $C$ elements are assumed to be uncertain; thus, the uncertainty budget is the number of uncertain matrix $C$ elements, which selects a value from the $\left[0,\left|j_{1}\right|\right]$ range as $J_{1}=\left\{j \mid d_{j}>0\right\}$.

The uncertainty budget actually controls the extent to which the problem is robust. If $\Gamma_{1}=0$, the uncertainty effect of all undetermined problem parameters is not considered. If 
$\Gamma_{1}=\left|J_{1}\right|$, then the uncertainty effect of all undetermined problem parameters is considered. This helps us define the robust optimization problem as follows:

$$
\begin{array}{lc}
\text { Maximize } & \sum_{j} c_{j} x_{j}-z_{1} \Gamma_{1}-\sum_{j \in J_{1}} q_{1 j} \\
\text { subject to : } & \\
z_{1}+q_{1 j} \geq d_{j} y_{j} & \forall j \in J_{1} \\
x_{j} \leq y_{j} & \forall j \\
q_{1} \geq 0 & \forall j \in J_{1} \\
y_{j} \geq 0 & \forall j \\
z_{1}>0 & \forall i \in I \\
a_{i} x \leq b_{i} &
\end{array}
$$

The constraints added to the above model were obtained using duality theory and linearization. The above robust optimization model assumed that the $c_{j}$ parameter was uncertain, as these parameters select a value from the $\left[c_{j}, c_{j}+d_{j}\right]$ range. Variables $z_{1}, q_{1 j}$, and $y_{j}$ are duality and slack variables, respectively, so that the undetermined parameter selects the worst values [22].

Figure 2 is the flowchart of robust optimization implementation in this study.

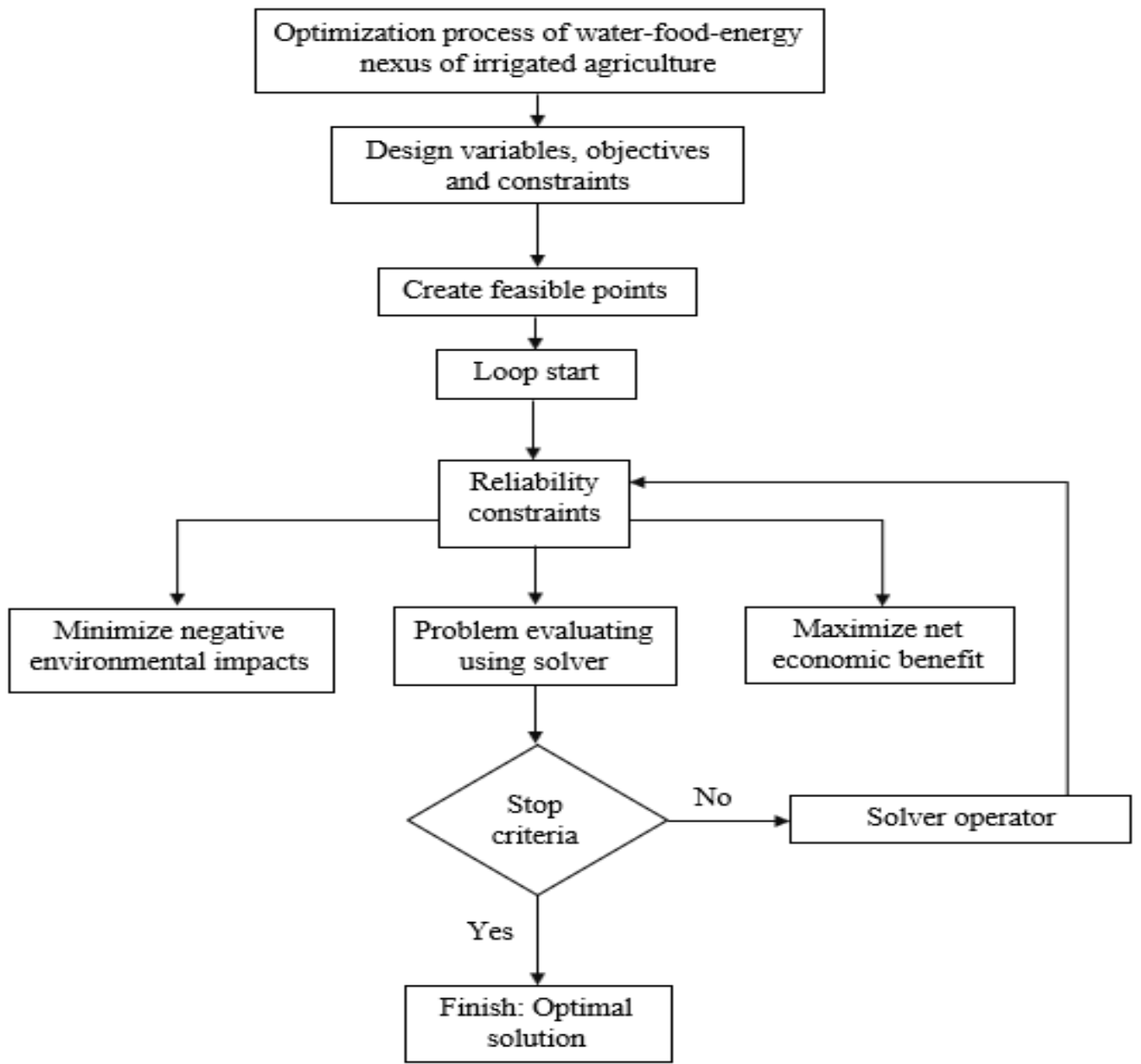

Figure 2. The flowchart of robust optimization implementation in this study.

In the study, with the utilization of the MATLAB software, after defining the variables, objective functions, and assumed constraints and then extracting a set of feasible solutions, 
we sought to find the best point (assuming an uncertain value for constraints) from among a set of extracted solutions.

\section{Problem Formulation}

We developed a model for integrated management of an electrical-energy-water-food nexus in the agricultural sector and for reaching the two objective functions of maximum economic profit and minimum greenhouse gas emissions in the nexus considering the constraints like access to electrical energy, surface and underground water resources, food resources, and land.

\subsection{Objective Functions}

\subsubsection{Maximizing Nexus Profit}

One of the main goals of any system is to increase its net profit. As we know, profit in any system is obtained by subtracting the total cost from the total revenue. Equation (6) is the nexus profit maximization objective function. As shown in Equation (7), the revenue stated in Equation (6) is derived from the production of a variety of foods. Moreover, as shown in Equation (8), the cost stated in Equation (6) includes the cost of energy needed for the water supply, the cost of energy needed for the food supply, and the cost of water supply needed for the food supply. As Equation (9) shows, the cost of energy needed for the water supply is itself a sum of three costs, including the cost of energy for irrigation using surface water, irrigation using groundwater, and the energy for drainage, explained in Equations (10)-(12), respectively. The cost of energy needed for the food supply, as seen in Equation (13), is composed of different components like the cost of supply of chemical fertilizers, pesticides, agricultural machinery, agricultural films, seeds, and labor. Equation (14) is the cost of the water supply needed for food preparation with two parts considering the price for surface water and groundwater.

$$
\begin{aligned}
& \max F N P=\max \{R-C\} \\
& R=\sum_{i=1}^{I} \sum_{p=1}^{P} P C_{p} \cdot Y A_{p} \cdot A_{i p} \\
& C=E C W+E C F+W C F \\
& E C W=E C I_{s w}+E C I_{g w}+E C D \\
& E C I_{s w}=E C \cdot\left[\frac{H I_{s w}}{102 \times 3.6 \cdot \mu_{s w}}\left(\sum_{i=1}^{I} \sum_{p=1}^{P} I Q_{\text {swip }} \cdot A_{i p}\right)\right] \\
& E C I_{g w}=E C \cdot\left[\frac{H_{\text {Lift }}+H_{n}+H_{\text {lossess }}}{102 \times 3.6 \cdot \mu_{p} \cdot \mu_{m}}\left(\sum_{i=1}^{I} \sum_{p=1}^{P} I Q_{\text {gwip }} \cdot A_{i p}\right)\right] \\
& E C D=E C \cdot\left[\sum_{i=1}^{I} \frac{H D_{i}}{102 \times 3.6 \cdot \mu_{d r a i}}\left(\sum_{p=1}^{P} D M_{p} \cdot T_{p}\right) \cdot A_{i p}\right] \\
& E C F=\sum_{i=1}^{I} A_{i p} \sum_{p=1}^{P}\left(\delta_{p f e r}+\delta_{\text {ppes }}+\delta_{\text {pmac }}+\delta_{p f i l m}+\delta_{\text {pseed }}+\delta_{\text {plabour }}\right) \\
& W C F=\sum_{i=1}^{I} W P_{\text {swi }}\left(\sum_{p=1}^{P} I Q_{\text {swip }} \cdot A_{i p}\right)+\sum_{i=1}^{I} W P_{\text {gwi }}\left(\sum_{p=1}^{P} I Q_{\text {gwip }} \cdot A_{i p}\right)
\end{aligned}
$$

\subsubsection{Minimizing $\mathrm{CO}_{2}$ Production and Water Pollution}

Another key goal to be considered besides reaching the maximum economic profit is minimizing the adverse effects that one must consider regarding the environment. As 
Equation (15) shows, this minimization has two parts: minimization of $\mathrm{CO}_{2}$ emissions and water pollution, expressed in Equations (16) and (17), respectively.

$$
\begin{gathered}
\min F_{E I}=\min \{A E+W E P\} \\
A E=\sum_{i=1}^{I} \sum_{p=1}^{P}\left[\left(C E F \cdot F_{i}+C E P \cdot P_{i}+C E D \cdot A M_{i}+C E A F \cdot A F_{i}\right) \cdot A_{i p}+(C E P L+C E I) \cdot A_{i p}\right] \\
W E P=\sum_{i=1}^{I} \sum_{p=1}^{P}\left[\left(P E I_{C O D_{c r}}+P E I_{N H_{3}-N}+P E I_{T N}+P E I_{T P}\right) \cdot A_{i p}+(L N+L P) \cdot A_{i p}\right]
\end{gathered}
$$

\subsection{Constraints}

Besides reaching the objective functions, one needs to consider and observe a series of requirements to be modeled as constraints along with the objective functions. There are six constraints in the nexus that were considered, which are examined in the following. The level of access to surface and groundwater in paddy fields and drylands must not exceed the value of surface and groundwater in the nexus as raised in Equations (18) and (19), respectively. We need electrical energy to collect surface and groundwater because of the use of electric pumps. Thus, the required electrical energy must not exceed the allowable range of access to electrical energy in the nexus. This constraint is shown in Equation (20). The population in the nexus determines the food needed for consumption and must specifically match the food produced in the nexus. This constraint is specified in Equation (21). According to Equation (22), depending on the food needed in each area, the range of the area needed for irrigation must be determined. As a definite constraint, the values of all decision variables in an optimization must not be negative as specified in Equations (23)-(26).

$$
\begin{aligned}
& \sum_{p=1}^{p_{1}}\left(I Q_{\text {swip }} \cdot A_{i p}\right) / \eta_{\text {swpf }}+\sum_{p=p_{1}+1}^{P}\left(I Q_{\text {swip }} \cdot A_{i p}\right) / \eta_{\text {swdl }} \leq S W A_{i} \quad \forall i \\
& \sum_{p=1}^{p_{1}}\left(I Q_{\text {gwip }} \cdot A_{i p}\right) / \eta_{\text {gwpf }}+\sum_{p=p_{1}+1}^{P}\left(I Q_{\text {gwip }} \cdot A_{i p}\right) / \eta_{g w d l} \leq G W I A_{i} \quad \forall i \\
& \quad \sum_{i=1}^{I}\left(G W I A_{i}-G W L_{i}-G W I_{i}\right) \leq T G W A \\
& \frac{\left(\frac{H I s w}{\mu_{s w}} \sum_{p=1}^{P} I Q_{\text {swip }} \cdot A_{i p}+\frac{H_{l i f t}+H_{n}+f_{\text {lossess }}}{\mu_{p} \cdot \mu_{m}} \sum_{p=1}^{P} I Q_{\text {gwip }} \cdot A_{i p}+\frac{H D_{i}}{\mu_{\text {drai }}} \sum_{p=1}^{P} D M_{i p} \cdot T_{i p} \cdot A_{i p}\right)}{102 \times 3.6} \leq E W_{i} \\
& \sum_{i=1}^{I} E W_{i} \leq E W A
\end{aligned}
$$

\section{Real Case Study}

We implemented the model using information received from an electrical-energywater-food nexus in "Fujian," northeastern China, to implement robust optimization 
in a real case study $[23,24]$. The highest factor of water consumption in this city is the agricultural sector with a cultivated area of 5 hectares. Corn, soybean, and rice are the three main products in these areas, considered in this paper too. This cultivated area is divided into four parts: "Songhuajiang," "Jinshan," "Huama," and "Toulin." These were called Zone 1 (or A), Zone 2 (or B), Zone 3 (or C), and Zone 4 (or D), respectively, for ease of expression. Four electric pumps are used in these four areas, the technical specifications of which are shown in Table 1. The optimal allocation of electrical energy, water, and land resources in these areas is a major challenge. Robust optimization has been implemented while developing the model to solve this challenge and to increase the profit on the one hand and reduce the adverse environmental effects on the other. The government reports of "Fujin," annual statistical reports, and the reports obtained from water measuring stations in these four areas were used in the study to collect the information needed for the four areas stated $[25,26]$. We examine some of the collected information. The prices of soybean products, corn, and rice and the costs of fertilizers, pesticides, agricultural machinery, seeds, labor, agricultural film, and drainage systems for all three products are shown in Table 2. Table 3 is the use of fertilizers, pesticides, diesel, groundwater, and population in the four areas. The cost of using ground and surface water per cubic meter was CNY 0.29 and 0.16 , respectively. Other information like the land availability range and the share of surface and underground irrigation for each of the crops in the four areas is given in Table 4. In this study, the equilibrium limit was 0.4. The types of efficiencies, including surface and groundwater use efficiencies for paddy fields and drylands separately, pump efficiencies, and engine efficiencies are given in Table 5. The $\mathrm{CO}_{2}$ production and the causes of water pollution are stated in Table 6 .

Table 1. The technical specifications of pumps.

\begin{tabular}{cccc}
\hline Pump & Hydraulic Heads $(\mathbf{m})$ & Flow $\left(\mathbf{m}^{3} / \mathbf{s}\right)$ & Power $(\mathbf{k W})$ \\
\hline A & 1.40 & 4.20 & 110 \\
\hline B & 2.95 & 3.56 & 185 \\
\hline C & 2.55 & 0.71 & 37 \\
\hline D & 3.46 & 1.18 & 75 \\
\hline
\end{tabular}

Table 2. The parameters of crops.

\begin{tabular}{cccc}
\hline Parameter & Rice & Corn & Soybean \\
\hline $\mathrm{PC}_{\mathrm{p}}(\mathrm{CNY} / \mathrm{kg})$ & 3.16 & 2.25 & 5.40 \\
\hline$\delta_{\text {pfilm }}(\mathrm{CNY} / \mathrm{ha})$ & 2.1 & 2.1 & 2.1 \\
\hline$\delta_{\text {plabor }}(\mathrm{CNY} / \mathrm{ha})$ & 1361.4 & 1043.7 & 311.6 \\
\hline$\delta_{\text {pseed }}(\mathrm{CNY} / \mathrm{ha})$ & 320.4 & 350.9 & 476.7 \\
\hline$\delta_{\text {pmac }}(\mathrm{CNY} / \mathrm{ha})$ & 1566.3 & 973.1 & 846.9 \\
\hline$\delta_{\text {ppes }}(\mathrm{CNY} / \mathrm{ha})$ & 289.2 & 148.2 & 141.6 \\
\hline$\delta_{\text {pfer }}(\mathrm{CNY} / \mathrm{ha})$ & 885 & 801 & 645 \\
\hline $\mathrm{DM}_{\mathrm{p}}\left(\mathrm{m}^{3} / \mathrm{d} / \mathrm{ha}\right)$ & 80.35 & 67.39 & 67.39 \\
\hline
\end{tabular}


Table 3. Parameters for various zones.

\begin{tabular}{ccccc}
\hline Parameter & Zone 1 & Zone 2 & Zone 3 & Zone 4 \\
\hline $\mathrm{F}_{\mathrm{i}}(\mathrm{kg} / \mathrm{ha})$ & 1464.58 & 1179.36 & 464.22 & 348.52 \\
\hline $\mathrm{P}_{\mathrm{i}}(\mathrm{kg} / \mathrm{ha})$ & 15.48 & 3.99 & 1.57 & 2.07 \\
\hline $\mathrm{Am}_{\mathrm{i}}(\mathrm{kg} / \mathrm{ha})$ & 236.13 & 95.21 & 37.48 & 3.00 \\
\hline $\mathrm{AF}_{\mathrm{i}}(\mathrm{kg} / \mathrm{ha})$ & 9.29 & 0.92 & 0.36 & 0.30 \\
\hline $\mathrm{GWL}_{\mathrm{i}}\left(10^{4} \mathrm{~m}^{3}\right)$ & 81.00 & 291.00 & 109.00 & 183.00 \\
\hline $\mathrm{GWI}_{\mathrm{i}}\left(10^{4} \mathrm{~m}^{3}\right)$ & 41.00 & 908.00 & 106.00 & 272.00 \\
\hline $\mathrm{PO}_{\mathrm{i}}\left(10^{4}\right.$ people $)$ & 0.77 & 4.31 & 1.12 & 1.62 \\
\hline
\end{tabular}

Table 4. Parameters for various zones and crops.

\begin{tabular}{cccccc}
\hline Parameter & Crops & Zone 1 & Zone 2 & Zone 3 & Zone 4 \\
\hline \multirow{2}{*}{$\mathrm{A}_{\text {ipmin }}\left(10^{4} \mathrm{ha}\right)$} & Rice & 0.51 & 1.23 & 1.85 & 1.43 \\
\cline { 2 - 5 } & Corn & 0.02 & 0.19 & 0.38 & 0.84 \\
\cline { 2 - 5 } & Soybean & 0.002 & 0.09 & 0.17 & 0.45 \\
\cline { 2 - 5 } $\mathrm{A}_{\text {ipmax }}\left(10^{4} \mathrm{ha}\right)$ & Rice & 0.53 & 1.85 & 3.34 & 2.28 \\
\cline { 2 - 5 } & Corn & 0.03 & 0.69 & 1.37 & 1.77 \\
\cline { 2 - 5 } & Soybean & 0.004 & 0.32 & 0.62 & 0.95 \\
\cline { 2 - 5 } YA $_{\text {ip }}(\mathrm{kg} / \mathrm{ha})$ & Rice & 8465.67 & 8511.17 & 8511.17 & 7887.33 \\
\cline { 2 - 5 } & Corn & 9087.80 & 9142.80 & 9142.80 & 8545.83 \\
\hline \multirow{2}{*}{$\mathrm{IQ}_{\text {swip }}\left(\mathrm{m}^{3} / \mathrm{ha}\right)$} & Soybean & 1988.83 & 2151.33 & 2151.33 & 1917.67 \\
\cline { 2 - 5 } & Rice & 3648.99 & 3668.61 & 3668.61 & 3399.71 \\
\cline { 2 - 5 } & Corn & 1529.50 & 1507.24 & 1507.24 & 1349.34 \\
\hline \multirow{2}{*}{$\mathrm{IQ}_{\text {gwip }}\left(\mathrm{m}^{3} / \mathrm{ha}\right)$} & Soybean & 1285.88 & 1390.95 & 1390.95 & 1239.87 \\
\cline { 2 - 5 } & Rice & 1216.33 & 1222.87 & 1222.87 & 1133.24 \\
\cline { 2 - 5 } & Corn & 509.83 & 502.41 & 502.41 & 449.78 \\
\hline
\end{tabular}

Table 5. Parameters for various efficiencies.

\begin{tabular}{cc}
\hline Parameter & Value \\
\hline$\eta_{\text {swpf }}$ & 0.51 \\
\hline$\eta_{\text {swdl }}$ & 0.53 \\
\hline$\eta_{\text {gwpf }}$ & 0.75 \\
\hline$\eta_{\text {gwdl }}$ & 0.78 \\
\hline$\mu_{\mathrm{p}}$ & 0.8 \\
\hline$\mu_{\mathrm{m}}$ & 0.4 \\
\hline$\mu_{\mathrm{sw}}$ & 0.5 \\
\hline
\end{tabular}


Table 6. The $\mathrm{CO}_{2}$ production and the causes of water pollution.

\begin{tabular}{cc}
\hline Parameter & Value \\
\hline $\mathrm{CEF}\left(\mathrm{kgco}_{2} / \mathrm{kg}\right)$ & 0.9 \\
\hline $\mathrm{CEP}\left(\mathrm{kgco}_{2} / \mathrm{kg}\right)$ & 4.93 \\
\hline $\mathrm{CED}\left(\mathrm{kgcO}_{2} / \mathrm{kg}\right)$ & 0.5927 \\
\hline $\mathrm{CEAF}\left(\mathrm{kgco}_{2} / \mathrm{kg}\right)$ & 5.18 \\
\hline $\mathrm{CEPL}\left(\mathrm{kgco}_{2} / \mathrm{kg}\right)$ & 312.6 \\
\hline $\mathrm{CEI}\left(\mathrm{kgcO}_{2} / \mathrm{kg}\right)$ & 226.48 \\
\hline $\mathrm{PEI}_{\mathrm{CODcr}}(\mathrm{kg} / \mathrm{ha})$ & 150 \\
\hline $\mathrm{PEI}_{\mathrm{NH} 3-\mathrm{N}}(\mathrm{kg} / \mathrm{ha})$ & 11.85 \\
\hline $\mathrm{PEI}_{\mathrm{TN}}(\mathrm{kg} / \mathrm{ha})$ & 171.75 \\
\hline $\mathrm{PEI}_{\mathrm{TP}}(\mathrm{kg} / \mathrm{ha})$ & 62.25 \\
\hline $\mathrm{LN}(\mathrm{kg} / \mathrm{ha})$ & 0.687 \\
\hline $\mathrm{LP}(\mathrm{kg} / \mathrm{ha})$ & 0.261 \\
\hline
\end{tabular}

\section{Evaluation of the Results}

As stated in the previous sections, a model was developed for the optimal allocation of electrical energy, water, and land resources in this study using robust optimization and specifically considering the existing uncertainties. Moreover, the two objective functions of maximum economic profit and minimum adverse environmental effects were achieved simultaneously.

After defining the variables, objective functions, and assumed constraints and then extracting a set of feasible solutions, we sought to find the best point (assuming an uncertain value for constraints) from among a set of extracted solutions. Of the 1000 feasible points, the optimal point at which both objective functions were reached simultaneously is shown in Figure 3. Moreover, Figures 4-7 show the revenue, cost, $\mathrm{CO}_{2}$ production, and water pollution of all 1000 feasible points as well as the optimal point, respectively. The optimal land allocation for planting corn, rice, and soybeans in each of the four areas is given in Figure 8 . The access to the surface and groundwater as well as the available electrical energy in each of the four areas are given in Figures 9 and 10, respectively.

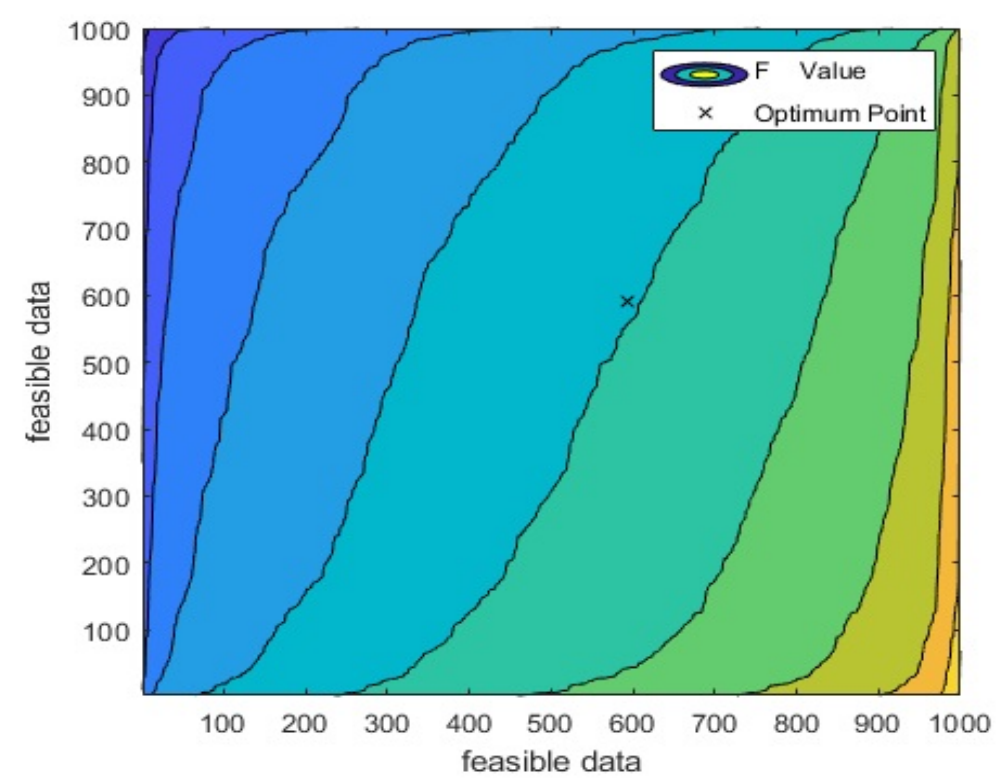

Figure 3. The feasible points and optimal point. 


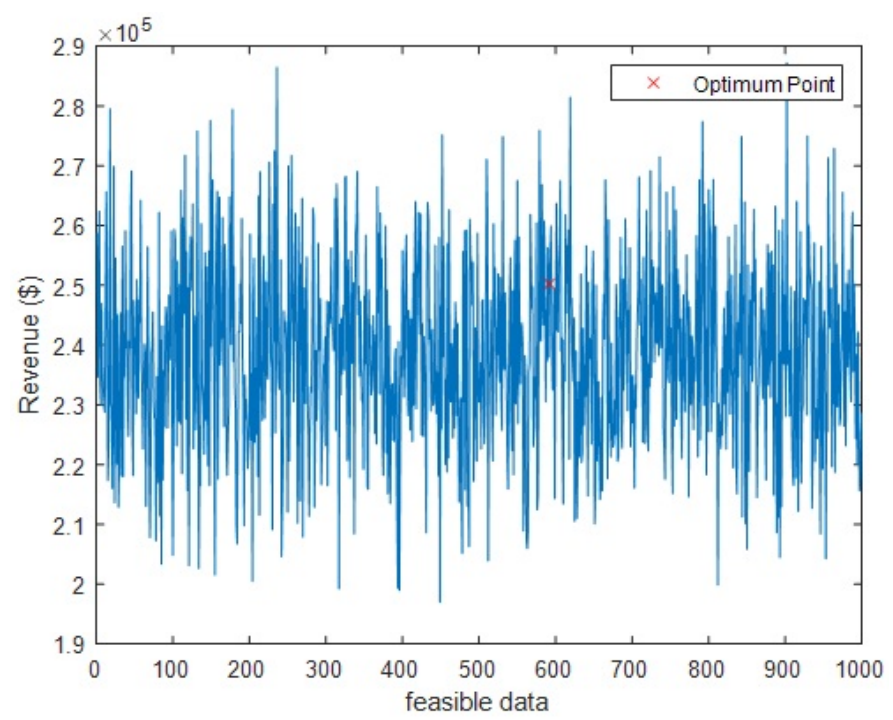

Figure 4. The revenue in all feasible points.

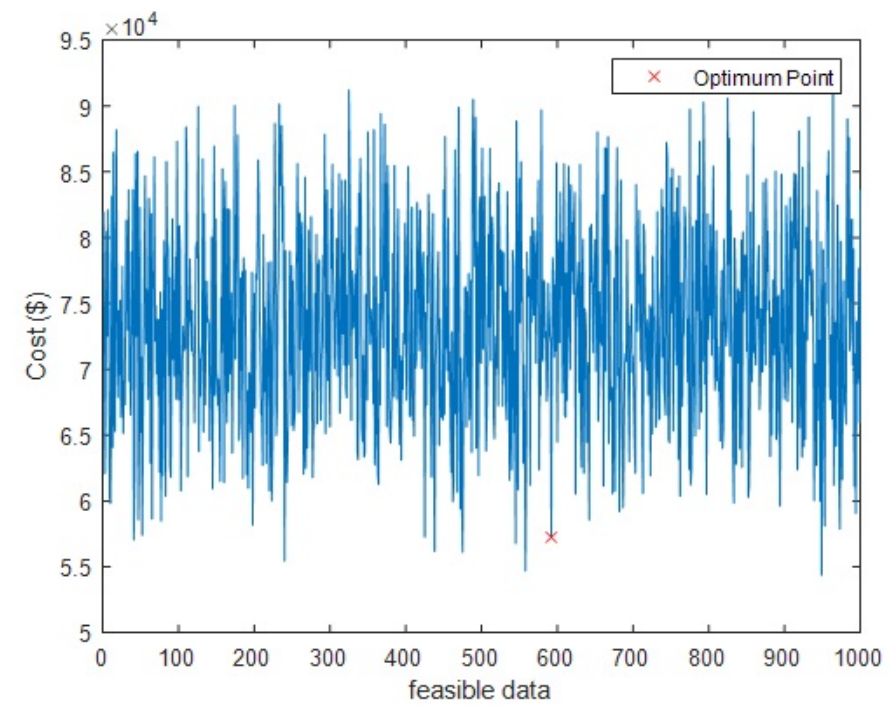

Figure 5. The cost in all feasible points.

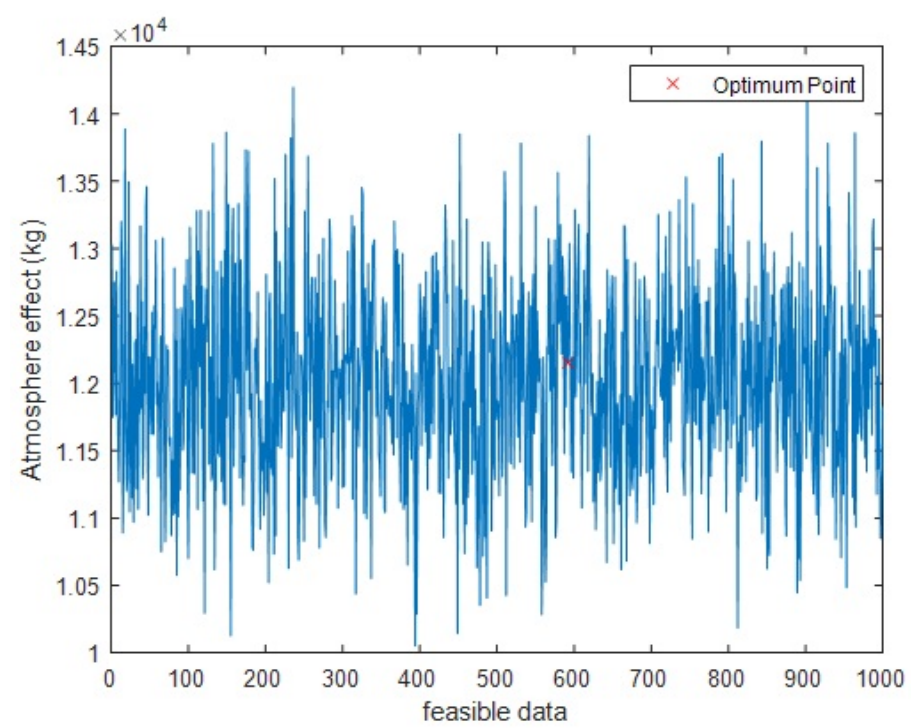

Figure 6. The $\mathrm{CO}_{2}$ production in all feasible points. 


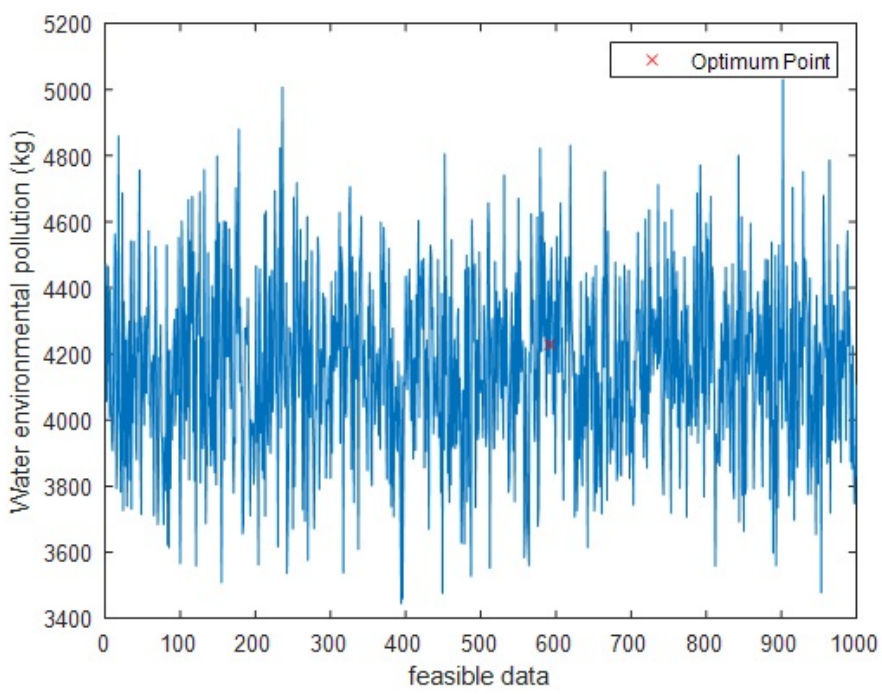

Figure 7. The water pollution in all feasible points.

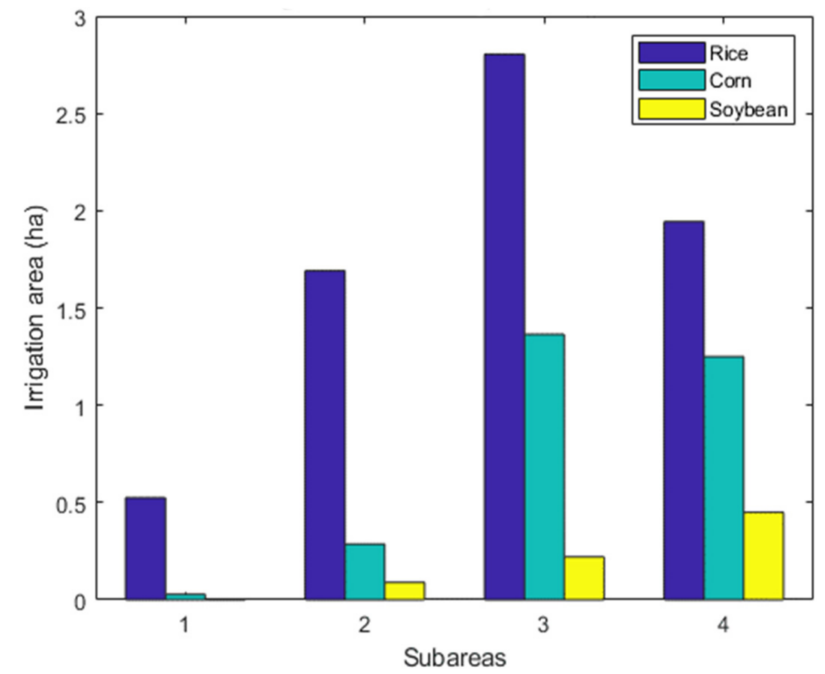

Figure 8. The optimal land allocation for planting corn, rice, and soybeans in each of the four areas.

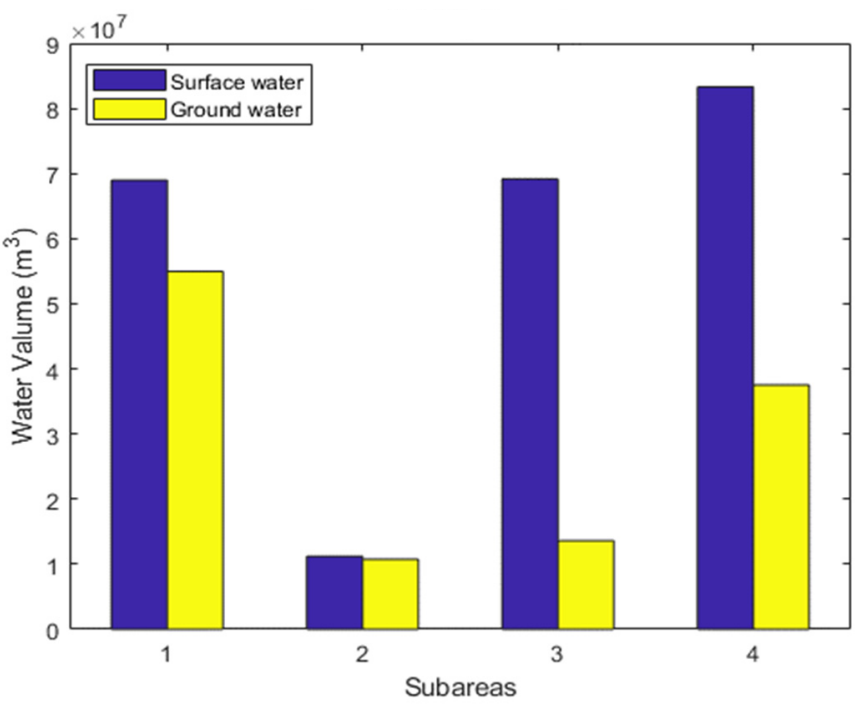

Figure 9. The access to the surface and groundwater in each of the four areas. 


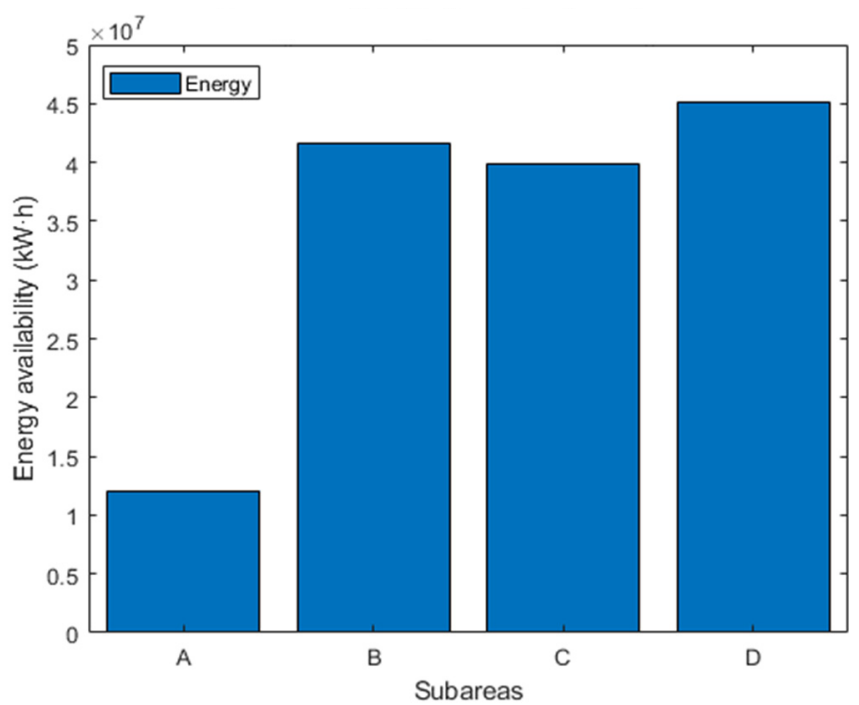

Figure 10. The available electrical energy in each of the four areas.

As is seen, using the obtained results, the ability to properly manage electrical energy, water, and food resources is provided, and thus the possibility of agricultural development, on the one hand, and optimal allocation of electrical energy resources, water resources, and land, on the other, is brought about.

Studies on the nexus provide promising perspectives on the relationship between water, electrical energy, and food from different perspectives. In future studies, more research on system boundaries, data uncertainty and modeling, the nexus mechanism, and system evaluation can be considered by researchers.

\section{Conclusions}

The close relationship and the reciprocal effects of electrical energy, water, and food resources, being critical resources across the world, are undeniable. The key to agricultural development, and optimal allocation of electrical energy, water, and earth resources, is the ability to appropriately manage electrical energy, water, and food resources, which involves many uncertainties. This study developed a model for a region in northern China using robust optimization by specifically considering existing uncertainties in order to optimally allocate electrical energy, water, and earth resources. The findings suggested that greenhouse gas production was reduced to its lowest level possible, while the highest economic return was achieved. The findings not only confirmed the close relationship between electrical energy, water, and food resources but also indicated the effectiveness of the proposed method for sustainable agricultural sector management.

Author Contributions: Conceptualization, M.A.H.; methodology, M.A.H.; software, M.A.H.; validation, N.T.K. and B.M.-I.; writing-original draft preparation, M.A.H. and A.S.; writing-review and editing, M.A.H. and A.S.; project administration, N.T.K. and B.M.-I. All authors have read and agreed to the published version of the manuscript.

Funding: This research received no external funding.

Institutional Review Board Statement: Not applicable.

Informed Consent Statement: Not applicable.

Data Availability Statement: The government reports of "Fujin," annual statistical reports, and the reports obtained from water measuring stations ("Songhuajiang," "Inshan," "Huama," and "Toulin") have been used in the study to collect the information needed for the four areas stated.

Conflicts of Interest: The authors declare no conflict of interest. 


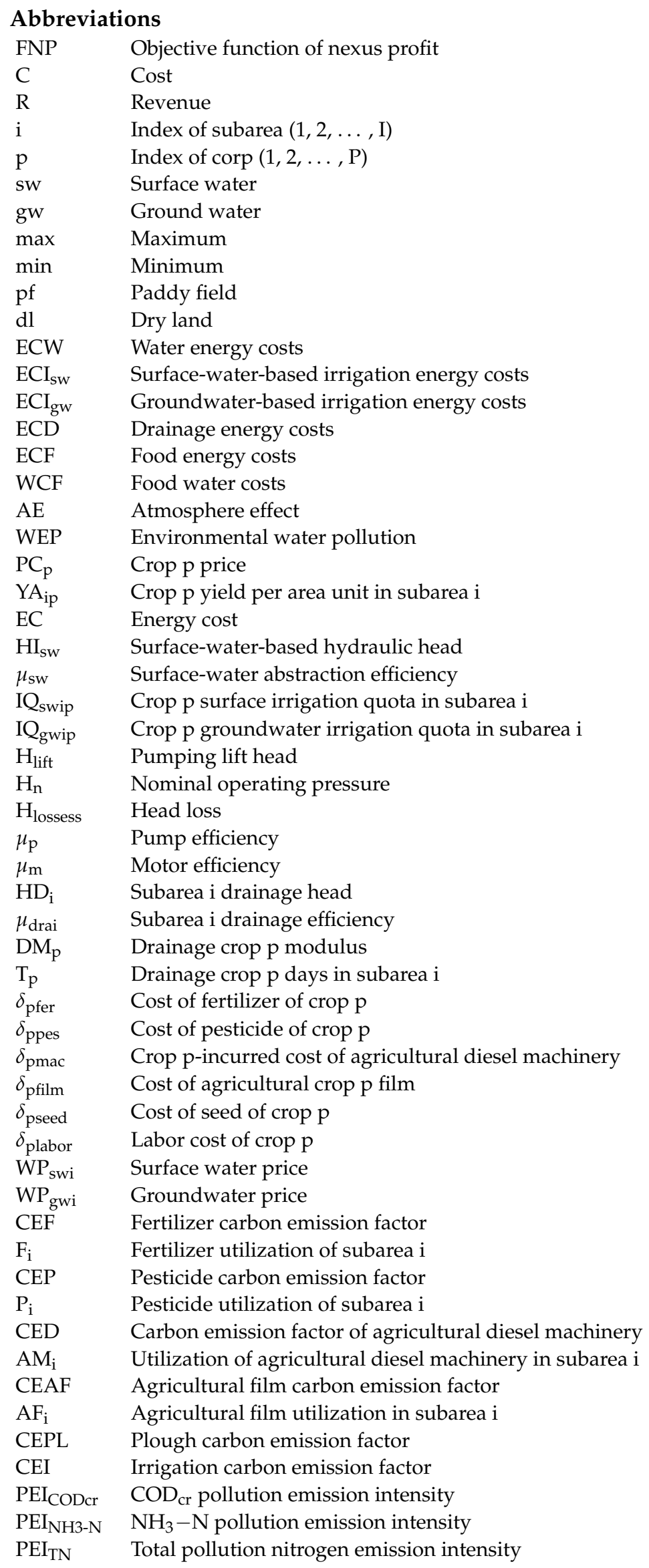




$\begin{array}{ll}\mathrm{PEI}_{\mathrm{TP}} & \text { Total pollution phosphorus emission intensity } \\ \mathrm{LN}_{\mathrm{i}} & \text { Nitrogen leaching in subarea i } \\ \mathrm{LP}_{\mathrm{i}} & \text { Phosphorus leaching in subarea i } \\ \eta_{\mathrm{swpf}} & \text { Surface-water utilization for paddy field efficiency } \\ \eta_{\mathrm{swdl}} & \text { Surface-water utilization for dry land efficiency } \\ \mathrm{r} & \text { Water diversion ratio to rivers } \\ \mathrm{Q} & \text { Runoff volume } \\ \eta_{\mathrm{gwpf}} & \text { Groundwater utilization for paddy field efficiency } \\ \eta_{\mathrm{gwdl}} & \text { Groundwater utilization for dry land efficiency } \\ \mathrm{GWIA}_{\mathrm{i}} & \text { Groundwater availability for irrigated subarea i agriculture } \\ \mathrm{GWL}_{\mathrm{i}} & \text { Utilization of groundwater for living in subarea i } \\ \mathrm{GWI}_{\mathrm{i}} & \text { Groundwater industry utilization in subarea i } \\ \mathrm{TGWA} & \text { Total groundwater availability } \\ \mathrm{EWA} & \text { Total water energy availability } \\ \mathrm{PO}_{\mathrm{i}} & \text { Subarea i pollution } \\ \mathrm{FD}_{\mathrm{B}} & \text { Food demand } \\ \mathrm{ER} & \text { Effective rainfall } \\ \theta & \text { Equity threshold } \\ \mathrm{A}_{\mathrm{ipmin}} & \text { Lower land availability limits of crop p in subarea i } \\ \mathrm{A}_{\mathrm{ipmax}} & \text { Upper land availability limits of crop p in subarea i } \\ \mathrm{A}_{\mathrm{ip}} & \text { Irrigation crop p area in subarea i } \\ \mathrm{SWA}_{\mathrm{i}} & \text { Surface-water availability for subarea i } \\ \mathrm{GWAI}_{\mathrm{i}} & \text { Groundwater availability for irrigated subarea i agriculture } \\ \mathrm{EWi} & \text { Water energy availability for subarea i } \\ & \end{array}$

\section{References}

1. Zhang, P.; Zhang, L.; Chang, Y.; Xu, M.; Hao, Y.; Liang, S.; Liu, G.; Yang, Z.; Wang, C. Food-energy-water (FEW) nexus for urban sustainability: A comprehensive review. Resour. Conserv. Recycl. 2019, 142, 215-224. [CrossRef]

2. Esmaeil, A.; Benjamin, M.; Behnam, M.I.; Tetsuo, T. The Role of Renewable Energy Resources in Sustainability of Water Desalination as a Potential Fresh-Water Source: An Updated Review. Sustainability 2020, 12, 5233. [CrossRef]

3. Hamdi, A.; Maryam, S.; Behnam, M.I. Food, Energy and Water Nexus: A Brief Review of Definitions, Research, and Challenges. Inventions 2020, 5, 56. [CrossRef]

4. Oikonomou, K.; Parvania, M. Optimal Coordination of Water Distribution Energy Flexibility with Power Systems Operation. IEEE Trans. Smart Grid 2018, 10, 1101-1110. [CrossRef]

5. Wang, X.; Dam, H.; Triantafyllidis, C.; Koppelaar, R.; Shah, N. Energy-water nexus design and operation towards the sustainable development goals. Comput. Chem. Eng. 2019, 124, 162-171. [CrossRef]

6. Esmaeil, A.; Benjamin, M.; Seiichi, O.; Behnam, M.I.; Tetsuo, T. An Integrated Planning Framework for Sustainable Water and Energy Supply. Sustainability 2020, 12, 4295. [CrossRef]

7. Zhang, C.; Chen, X.; Li, Y.; Ding, W.; Fu, G. Water-energy-food nexus: Concepts, questions and methodologies. J. Clean. Prod. 2018, 195, 625-639. [CrossRef]

8. Morteza, N.H.; Behnam, M.I.; Somayeh, A. Optimal operation of multi-carrier energy networks with gas, power, heating, and water energy sources considering different energy storage technologies. J. Energy Storage 2020, 31, 101574. [CrossRef]

9. Chen, I.-C.; Wang, Y.H.; Lin, W.; Ma, H.W. Assessing the risk of the food-energy-water nexus of urban metabolism: A case study of Kinmen Island, Taiwan. Ecol. Indic. 2020, 110, 105861. [CrossRef]

10. Ahangari Hassas, M.; Taghizadegan Kalantari, N. The energy-water-food nexus: Concept, challenges and prospects. JEMT 2022, 6, 9-14. [CrossRef]

11. Tian, H.; Lu, C.; Pan, S.; Yang, J.; Miao, R.; Ren, W.; Yu, Q.; Fu, B.; Jin, F.F.; Lu, Y.; et al. Optimizing resource use efficiencies in the food-energy-water nexus for sustainable agriculture: From conceptual model to decision support system. Curr. Opin. Environ. Sustain. 2018, 33, 104-113. [CrossRef]

12. Gondhalekar, D.; Ramsauer, T. Nexus city: Operationalizing the urban water-energy-food nexus for climate change adaptation in Munich, Germany. Urban. Clim. 2017, 19, 28-40. [CrossRef]

13. Conway, D.; Garderen, E.A.; Deryng, D.; Dorling, S.; Krueger, T.; Landman, W.; Lankford, B.; Lebek, K.; Osborn, T.; Ringler, C.; et al. Climate and southern Africa's water-energy-food nexus. Nat. Clim. Chang. 2015, 5, 837-846. [CrossRef]

14. Endo, A.; Tsurita, I.; Burnett, K.; Orencio, P.M. A review of the current state of research on the water, energy, and food nexus. J. Hydrol. Reg. Stud. 2017, 11, 20-30. [CrossRef]

15. Mukuve, F.M.; Fenner, R.A. The influence of water, land, energy and soil-nutrient resource interactions on the food system in Uganda. Food Policy 2015, 51, 24-37. [CrossRef]

16. Ozturk, I. Sustainability in the food-energy-water nexus: Evidence from BRICS (Brazil, the Russian Federation, India, China, and South Africa) countries. Energy 2015, 93, 999-1010. [CrossRef] 
17. Santhosh, A.; Farid, A.M.; Youcef-Toumi, K. Real-time economic dispatch for the supply side of the energy-water nexus. Appl. Energy 2014, 122, 42-52. [CrossRef]

18. Yang, J.; Su, C. Robust optimization of microgrid based on renewable distributed power generation and load demand uncertainty. Energy 2021, 223, 120043. [CrossRef]

19. Singh, S.; Biswal, M.P. A robust optimization model under uncertain environment: An application in production planning Comput. Ind. Eng. 2021, 155, 107169. [CrossRef]

20. Coppitters, D.; Paepe, W.; Contino, F. Robust design optimization of a photovoltaic-battery-heat pump system with thermal storage under aleatory and epistemic uncertainty. Energy 2021, 229, 120692. [CrossRef]

21. Yu, Z.; Zhengshuo, L.; Guangrui, W. Study on leveraging wind farms' robust reactive power range for uncertain power system reactive power optimization. Appl. Energy 2021, 298, 117130. [CrossRef]

22. Sudlop, R.; Hiroshi, M. Hybrid stochastic robust optimization and robust optimization for energy planning-A social impactconstrained case study. Appl. Energy 2021, 298, 117258. [CrossRef]

23. Mo, L.; Qiang, F.; Vijay, S.; Liu, D.; Tianxiao, L. Stochastic multi-objective modeling for optimization of water-food-energy nexus of irrigated agriculture. Adv. Water Resour. 2019, 127, 209-224. [CrossRef]

24. Daccache, A.; Ciurana, J.S.; Rodriguez Diaz, J.A.; Knox, J.W. Water and energy footprint of irrigated agriculture in the Mediterranean region. Environ. Res. Lett. 2014, 9, 124014. [CrossRef]

25. Yang, G.; Huo, L.; Vijay, S.; Ren, C. Optimization of the irrigation water resources for Shijin irrigation district in north China Agric. Water Manag. 2015, 158, 82-98. [CrossRef]

26. Vito, R.; Portoghese, I.; Pagano, A.; Fratino, U.; Vurro, M. An index-based approach for the sustainability assessment of irrigation practice based on the water-energy-food nexus framework. Adv. Water Resour. 2017, 110, 423-436. [CrossRef] 